\title{
Gamification Effects on Motivation and Learning: Application to Primary and College Students
}

\author{
Theresa A. Papp \\ University of Saskatchewan, Canada
}

\begin{abstract}
This manuscript reports the effects of gamification elements on primary and college students' motivation and learning. This mixed methods research reports two years of data collection of primary and college students' reflections, pre- and post-test results, and survey results as well as observations made by the author. Business communication classes and mathematics classes experienced gamification by introducing game elements and frameworks in the classrooms while maintaining the integrity of the learning outcomes. Students expressed increased motivation and engagement at both the primary and college level as well as improved learning.
\end{abstract}

\section{Introduction}

Canada is considered a First World Country. We are a developed nation with what most would consider an advanced economy that is rich, developed, and industrialized with a high standard of living. Given the status of Canada compared to Third and Fourth World countries, we should be enjoying a human capital that thrives and experiencing a 95\% high school graduation rate as other countries such as Finland [1]. However, Canada and the United States graduation rates were $76 \%$ and $72 \%$ respectively [1]. Graduation from high school is a pre-requisite for students to attend higher learning institutions. People that do not graduate or only acquire a high school education tend to gain employment at minimum wage levels. There then becomes a vicious cycle of low education levels for people resulting in low-paying employment. Poverty continues and places these people among the working poor resulting in more children growing up in poverty and being disadvantaged. Low minimum wages and inflated living costs prohibit the ability to meet the costs of living. Receiving a high school diploma and continuing to higher education provides certifications, diplomas, degrees or red-seal technical trades recognitions. Postsecondary education, in turn, will typically provide better-paying employment compared to not graduating from high school which often leads to minimum wage jobs. In Canada, anything less than a 95\% high school graduation rate should not be acceptable.

The education system had changed little from a century ago with the Industrial Age when its purpose was to prepare students to become routine workers in factories. The introduction of whiteboards, digital projectors, and other technology argue how advanced the education system has become; however, the whiteboard has replaced the chalkboards and projectors the textbook or papers. The teacher in many cases has remained the center of the learning and students are required to read the text, answer questions and perform tests on the material. Although education completion levels have increased due to the shift away from an agrarian society, there is still a shortfall of high school graduates. This paper will present the concept of gamification and empirical research addressing the effects gamification has had on intrinsic and extrinsic motivation, engagement and learning outcomes for learners at both the primary and college levels.

To set the tone, the significance of this paper warrants explanation. Canada falls short by nearly $20 \%$ in graduation rates as compared to Finland, and too many students are not succeeding in school. The existing schools and teaching practices need to change to help students experience motivation, relevance, and engagement. Research indicates these criteria improve learning and achievement in the classroom [2] [3] [4] [5]. Especially when students can experience the relevance of school topics and truly engage in the classroom this, in turn, stimulates inquisitiveness and imagination. Learning should go beyond transmission learning, reading the text, answering questions, and tests. The findings presented have the potential to improve learning achievement levels for all students.

Businesses have utilized gamification in marketing strategies creating customer loyalty resulting in success. The health and fitness industry has implemented gamification as well. With the emergence of Reality if Broken by Jane McGonical [6] the concept of gamification has gained momentum. Now classrooms are beginning to introduce gamification with the potential to improve education outcomes for all students.

This paper will introduce the concept of gamification, the terminology used in gamification and the benefits of incorporating these principles into the classroom as well as empirical data addressing the effects gamification has had on intrinsic and extrinsic motivation, engagement and learning outcomes of learners. What follows is a brief background of gamification in education, a definition and the game elements that are presented in the classroom. A literature review will be provided on gamification in 
education as well as the systematic mapping of categorical applications in education. The pedagogical theories that are present in gamification are presented. The paper provides a quantitative analysis of data collected from primary and college students on their experiences in a class that was gamified along with qualitative responses about the experience.

\section{Background: Gamification}

Gamification has been defined as the use of game design elements in non-game contexts such as education [7]. Gamification has been in existence for less than a decade and is a new term documented in 2008 that is a growing phenomenon [7]. The momentum that began over thirty years ago with the advent of the video game has now escalated and now games and game apps are part of everyday life for all ages of people. However, the concept has been recognized to hold value in 1954 by Mood and Specht [8]. In a government report, Mood and Specht stated "a virtue of gaming that is sometimes overlooked by those seeking grander goals . . . is its unparalleled advantages in training and educational programs. A game can easily be made fascinating enough to put over the dullest facts" (p. 12-13).

There remains a negative connotation surrounding the gamification concept. Perhaps this comes from the root word being game and that is equated to play, entertainment, nonproductivity, and having fun which typically is not associated with learning [9] [7] [10] [11]. On the other side of the continuum is the falsehood that gamification is a panacea for all learning and all learners. Gamification is supported by evidence-based research that legitimizes the use of learning theories and principles through its implementation verifying that the process is not just play. Gee [12] identified 36 learning principles that are present in the gamification process. These include critical learning, design, semiotic domains, meta level thinking, self-knowledge and achievement learning principles just to name a few. Ryan and Deci [13] provided research evidence on intrinsic and extrinsic motivation and that self-determination theory is evident in gamification as well as social learning theory [14]. Scaffolding is used throughout the gamification process [15]. Also present, is the theory of motivation [16] as well as flow theory [17].

Nah, Zeng, Telaprolu, Ayyappa, and Eschenbrenner [18] conducted a review of the literature on gamification in education. Their synthesis identified the design elements utilized to gamify education were the following: points, levels or stages, badges, leaderboards, prizes and rewards, progress bars, storyline, and feedback. Students experience motivation and engagement which enhances learning when these various game elements are used in a classroom situation [19].
Dicheva, Dichev, Agre, and Angelova [20] conducted a systematic mapping study of gamification in education from several research papers and revealed the categories of design principles included were: goals and challenges, personalization, rapid feedback, visible status, freedom of choice, freedom to fail, and social engagement. The most popular design principles were individual and group challenges where competition created social engagement and visible status were reported [20]. It was noted that most of the gamification of education and reported research was conducted in science, engineering, information and computer technology at the college level [20], [18].

Specific researchers that have implemented and conducted research on gamification have documented the effectiveness of using gamification in classrooms [12] [11] [19] [21]. Research has also indicated that there are benefits to playing video games that improve cognitive abilities (attention, focus and reaction time), motivation, emotional and social benefits [22]. Gee [12] stated, "in fact, the learning principles that good games incorporate are all strongly supported by contemporary research in cognitive science - the science that studies human thinking and learning through laboratory research, studies of the brain, and research at actual learning sites like classrooms and workplaces" (p. 1). Given the promising results and the grounding of theories and learning principles in the gamification process, more empirical research needs to be conducted. This study was carried out to discover the influences of gamification on students and learning in a non-technology discipline as well as the effects on learning outcomes. The following section will describe the research paradigm, the conceptual framework used to analyze the data, participant selection, and data collection.

\section{Research Methodology}

This study involved six business communication classes of college students and two mathematics classes comprised of grade four students. The purpose of this mixed research study is to identify the students' perception of the impact gamification had on their learning in the classes, using gamification elements. This study will present data collected using a survey instrument to report the students' opinions, experiences and perceived outcomes of the gamification process. The business communication data on gamification was collected over a two-year period with one year providing the qualitative data and the other the quantitative data. The qualitative data was derived from a reflective assignment each student completed. The grade four students were exclusively focused on multiplication and collected data through a pre-test and post-test to quantify if improved learned took place after the introduction of the gamification. These students were also part of a 
focus group that offered feedback to their experiences in the gamified classroom.

The hypothesis was that all students' from each class and grade level will express the perception of gamification would improve learning, engagement, and motivation. Grounded theory guided the research design. Glaser and Strauss [23] introduced grounded theory to the research community as a means to analyze data and build theory. Grounded theory is arduous and continuously compares and creates a hypothesis which transcends merely describing the collected data [24]. The conceptualization in grounded theory procedures takes the many participant responses and reveals patterns and categories. This approach to interpreting the data is for theory development. The research used purposeful sampling in which "the researcher selects particular elements from the population that will be representative or informative about the topic of interest" [25].

The research methods utilized in this study, for both the communications and mathematics classes comprised of four levels of analysis: 1) a case study of the different classes and student groups that completed the gamified experience with the same researcher, and 2) a survey that utilized a five-point Likert scale that reported the students' experiences, and 3) a focus group session with the mathematics students and a reflective report from the communication students, and 4) observations by the researcher during the gamification process [26] [27]. The qualitative component of the communications students' requested that the student provide a reflection report on their experiences of gamification in the classroom and provide insight about the course comparing the first half that was not gamified to the second half of the term that was gamified.

\subsection{Participant Selection and Data Collection}

The data was collected over a two-year period from the same school locations. At the college, there were three cohorts each academic year for a total of six classes of college students, which had experienced gamification by the same instructor on the same communication topics with a total of six classrooms with 65 and 64 students. One student group provided the quantitative data, and the other provided the qualitative data.

The mathematics data was collected from one school location over a two-year period with 22 and 20 respectively. The two classrooms were comprised of students between the ages of 9 to 11 years of age. The participants of the mathematics classes completed multiplication table sets as a pretest to determine a baseline of what they were proficient at calculating and to ascertain the focus of the intervention. Both groups of students were not proficient with the $7 \mathrm{X}$, $8 \mathrm{X}$, and $9 \mathrm{X}$ table. The post-tests were conducted after the gamification intervention to provide data on the impact on the learning. A survey was prepared and distributed to the students at the end of the intervention to determine attitudes towards the gamification elements and altered learning process.

The surveys and qualitative questions were crafted to garner insight into students' perceptions of the gamification process and their learning based on the research questions for this study. The survey consisted of four groups of questions. Two groups of questions were for demographic purposes, and the remaining sections of the survey were to answer the following research questions:

1. Do students experience increased motivation through gaming elements?

2. Do students perceive that they learned more from a gamification intervention?

3. Do students that experience a gamified classroom find learning more enjoyable?

4. Do students that play games regularly find gamification more enjoyable? (This question was directed to the college students)

\section{Limitations}

This research did present various limitations for both the college students as well as the primary students. For the mathematics classes, attendance was an issue. Students did not attend class regularly, and there were also school events scheduled that limited exposure to the gamified intervention with the mathematics classes. The limitation of inconsistent attendance translated into some students experiencing more learning opportunities through the gamification intervention than other students. The research was conducted in the last two months of the school year, May and June, and this is a time when student interest is waning compared to the beginning of a school year. Alternatively, the end of the school year could be an ideal time to conduct research and determine if engagement and motivations could be increased. The data set was small, and this also is a limitation.

The college students groups were also a small group of students. The survey was administered four months after the conclusion of the gamification intervention which may have had an adverse effect on the perceptions. The students were challenged as teams to fundraise for a charity and because this was a project-based activity as well as an altruistic activity in some instances makes it difficult to separate the effects of the gamification compared to the philanthropic outcomes. Some elements of gamification were able to be identified clearly and their effects on the students while other aspects were harder to separate the altruistic nature of the activity from the gamification process.

\section{The process explained}


I have been gamifying my classrooms for three years beginning with one cohort of 21 college students and expanding to multiple classes and courses. Implementing gamification into my classrooms eventually led to the research reported here at the middle school level with a math class and the business communications classes. To date, over ten classrooms have been gamified. To gamify a course is daunting and requires creativity and can be labor-intensive. How to begin is the hardest part. Forerunners in the field of gamification, such as Sheldon, had explained the process within a variety of technology or science courses. The gamification process is not about video games, software, or even computers. Critics may state this process is all about playing all day without learning. The process is about game elements used in the classroom. Each process will be described separately due to the difference in course material and age.

\subsection{Business communications}

At the beginning of the course, students learned how to compose a variety of documents. After the midterm exam, gamification was introduced. Students were placed into teams or guilds comprised of four to five students based on their interests. There were a total of 12 guilds, 4 guilds within each of the 3 cohorts.

As a class requirement, students created meeting agendas, conducted meetings as a chairperson and prepared minutes of the meetings as well as provided the class with a persuasive presentation. These were graded according to a standardized rubric that contributed to their final marks. The integrity of the learning outcomes and assignments were unchanged. The gamification created an overlay to the class without compromising the course material. Gaming elements were introduced into the classroom. I was the Game Master and would randomly expose the students to experience team quests or individual challenges. This would result in the guild earning experience points. The quests were based on course material that was demonstrated through an activity. In addition to completing the course learning requirements, the main activity that each group experienced was a project-based challenge to raise money for the charity of their choice. The students' groupings created a competitive atmosphere to see what group would raise the most money for their charity and what groups would have the highest experience points score. With the gamification design principle, the students set goals and group norms. Each team created their own set of rules of conduct and expectations for their members. They all had the same challenges and were exposed to equal opportunities to earn experience points. The fundraising dollars raised for each charity was not graded and did not contributed to experience points.
However, choosing a charity and deciding on how the groups were going to raise money demonstrated the design principle of choice and personalization of the goals set. Students would earn points for attendance and experienced various challenges in addition to prizes and awards. Peer pressure increased attendance, and this was rewarded with extra bonus points for the teams. Students were able to follow their progress and the status of their peers through a regularly updated leaderboard.

\subsection{Mathematics}

The focus of the mathematics gamification was targeted exclusively to improve the students' multiplication abilities. Teaching multiplication required a novel method as the typical rote memorizing was not effective based on the pre-tests to establish a baseline of knowledge. A pre-test of multiplication tables from 0 to 10 was administered to the students to determine prior knowledge (PK) before the start of the intervention. In particular, the focus was on the $7 \mathrm{X}, 8 \mathrm{X}$, and $9 \mathrm{X}$ tables. These timetables were the most difficult to master for this grade and age level. The pre-test gave a starting point to gauge the amount of learning the students experienced. The students were identified by the teacher to belong to three capability groupings (lowperforming, approaching or average, and meeting expectations).

I was introduced to the students as the Game Master and explained the research concept to them. The students immediately thought we would be playing video games. Gamification of the class was to use game elements without any computers or expensive software. As the Game Master, I had an avatar that represented me as a wizard with a magic wand and red hair. Before beginning the formal research, I came to the classroom often so they would be familiar with me. I was able to identify the students that were within the three different capability groups. I was primarily interested in the low-performing students as they appeared to be disengaged and often disruptive during class time. The intervention was over a period of nearly two months once all the parental consents and official documentation was received. The class time was approximately one hour duration and I attended the classroom two to three times a week when the school schedule allowed based on extracurricular activities planned at the end of the school year.

The students would call me Game Master when they saw me and were excited to anticipate what magic I was bringing to class. I began by creating a mood. I found a hallway that the lights could be shut off. I did dress as a wizard with a hat and cape on our first two exposures to magic math. My attire was novel for the students and created excitement, a gamification technique. Gummi worms provided 
incentive and each time we met as a group the students learned a new math magic trick that would provide the students a new way to learn and remember their multiplication. After learning a new math trick, each student would complete a multiplication worksheet consisting of 12 questions that represented the multiplication focus of the day as well as PK questions. The next time we got together, a couple of days later, the students would complete another small quiz of similar multiplication questions to establish retention of the previous learning. Each time I came to the school one or two groups would experience the math magic and review and learn more multiplication tricks. Student exposure to the intervention was inconsistent due to special school events, school outings and class attendance.

\section{The findings}

The gamification findings will be presented separately for the business communication students, and the grade four mathematics students. The quantitative and qualitative data is presented in the same manner. I will begin by providing my observations for each of the each of the groups, the results of the surveys and the interpretations of the data collected, followed by the qualitative information gathered from the students that participated. For both groups, the survey instrument utilized a 5-point Likert scale where 1 represented strongly disagrees and 5 representing strongly agree. The research questions guided the questions that the students answered.

\subsection{Business communications}

A trend had formed from the beginning of the semester that found that early morning classes were not well attended. Once the gamification process commenced, a dramatic change occurred in that attendance, particularly for the early morning classes. There were bonus points offered to the guilds that had all their members in attendance. Students would cheer as they were fixated on the door and watching the clock to see their classmates arrive. The overall challenge to raise money for a charity created a hype that elevated the energy in the classroom as they planned and discussed ideas. Also, the social engagement of the students increased as the student groups would voluntarily meet before school, at lunch, and after school to discuss ideas, gather donations or fundraise for their charity. The increased student meetings implied a positive impact gamification had on the students' engagement and motivation. The challenges and award of experience points appeared to build comradery. At the beginning of each class, the students would congregate around the leaderboard to see their guild's status and XP point level compared to the rest of the classes.
6.1.1. Demographics. There were 45 respondents to the survey. The participants that were between the ages of 18 to 25 were $80 \%$. Those that were between the ages of 26 and 30 represented $11 \%$ of the respondents, and $9 \%$ were over 31 years of age. The total participants were $69 \%$ Caucasian and $31 \%$ selfidentified Aboriginal students. The gender of the participants was $65 \%$ female and $35 \%$ male.

6.1.2. Motivation. Student groups were rewarded with XP and bonus points when their entire team was in attendance, and this was a strong motivator to attend class and for the competition. The leaderboard also enhanced student motivation as would the money generated through various fundraising activities held at the school. Students reported that they did not want to miss business communications classes at a rate of $71.7 \%$ and $86.6 \%$ of the students did not want to let down their teammates in the agree to strongly agree categories respectively. The students felt the business communications class was $42.2 \%$ more engaging than their other classes in the agree and strongly agree responses. Students also reported that $66.6 \%$ spent time outside of the classroom and by freely choosing to meet this was deemed to represent increased motivation. The students reported that team competition was enjoyable at a rate of $66.6 \%$ that agreed and strongly agreed with that statement.

6.1.3. Students' learning. The students' perception that they learned more from the gamification approach is embedded in the mechanics of how the course was modified. For example, the project-based approach and the challenge to raise money for their charity are not typical classroom strategies. Students perceived that they learned more from the fundraising activity and reported it as a practical method to learn the course material at a rate of $68.9 \%$ and $73.3 \%$ respectively within the agree and strongly agree Likert scale. The students felt that gamification was a method of putting theory into practice and a better way to learn than conventional teaching at a rate of $64.4 \%$ in the agree and strongly agree categories.

6.1.4. Intrinsically rewarding. Again, the altruistic nature of the class project and the challenge to fundraising for the charity of their choice may have altered the rankings and the students' perception of gamification. The students reported raising money for their charity made them feel proud at a score of $82.2 \%$ agreeing and strongly agreeing. More focused on the competition and gamification, the students reported that they enjoyed the competition against the other teams at a rate of $66.6 \%$ and felt gaining points for their team was fun at a rate of $40 \%$. Students reported they enjoyed participating in games and found them fun at a rate of $42.2 \%$ that agreed and strongly agreed. 
6.1.5. Game players versus the gamification approach. The survey had 45 respondents of which $80 \%$ were between the ages of 18 and 25 years. A low percentage of students reported that they played games online at a rate of $17.8 \%$ and $28.9 \%$ played on their phone. The data indicated that the majority of students did not play games regularly at a response rate of $75.5 \%$ of students disagreed and strongly disagreed.

6.1.6. Qualitative reports on gamification business communication. What follows are the comments that have been excerpted from a reflection assignment the students completed at the end of the gamification process. The students were asked to report on their experiences. The names provided are pseudonyms.

A common theme that emerged from the reflections was the gamification was enjoyable and a fresh approach to learning. The students felt it was a fun way to learn compared to regular textbook learning as in reading a module and answering the questions. Dan stated, "I believe gamifying this course was a great idea. It made the assignments exciting and competitive". Students also noted that they preferred an experiential learning approach through a project-based learning experience and appreciated the practical application. Abby reported, "These skills will be very valuable in the future and in my career. In gamifying this course, it made the whole experience more enjoyable".

The group and individual challenges sparked competition between the students and guilds. Peerpressure contributed to improved attendance. The teams were offered bonus points when all members were in attendance. Candace commented, "I believe the attendance bonus was a good idea. It pressured students to show up to class on time". Frank thought that gamification was a different approach to learning and stated, "Teams kept on task because of the competition aspect. They also tried harder to make it to every class because of the bonus marks". Many of the challenges were opportunities to learn about teamwork and to improve their problem-solving skills in an engaging and exciting manner. Holly commented:

The gamification of the class and group challenges proved to be a great way to build team skills and problem-solve together, as well as motivate members to complete all the tasks within an appropriate time frame. It's been a growing experience for me and I am glad to be able to say that I am taking necessary skills for the future away from this project.

\subsection{Mathematics}

6.2.1. The background information. Each time I met with the students, they were taught a new math trick. The students were then given a quiz that covered the multiplication taught along with multiplication questions that represented PK. The students demonstrated understanding by correctly answering their short quiz questions. Each time the students participated they received experience points (XP) and this was added to the leaderboard. Each correct answer provided on the quiz also contributed to their leaderboard scores. Experience points were also added after every retest was completed. Each quiz had 12 questions. Each student could earn a maximum of 1200 XP if they answered all the questions correctly. At the end of the intervention, some students had reached the level of Apprentice while others that had not attended class regularly successfully reached lower levels based on their XP. The levels began and progressed as follows: Initiate, Rookie, Neophyte, Apprentice, Journeyperson, Craftsperson, and Artisan. The leaderboard was presented each day the Game Master attended the classroom. The students were excited to see where they stood in comparison to their classmates.

6.2.2. The findings. The pre-tests determined the baseline for each student and their prior knowledge (PK). The results from the pre-test concluded that the majority of the students needed assistance in learning the 7X, 8X, and 9X multiplication tables. Only one student had met competency in the 9X table. After each gamified intervention, the students within the group were tested to determine recall of the math trick and again tested a few days later with similar questions as well as multiplication problems containing PK multiplication tables. The teacher had grouped the students into three capability groupings (low-performing, approaching, and meeting). All three groups improved. I had noticed that the lowperforming students did not engage in the regular classroom and were at times disruptive. However, when the same students were part of a smaller group of students that were participating in the gamified experience and learning math tricks they participated willingly and demonstrated the greatest gains in multiplication knowledge. In the final post-test, the students improved the $7 \mathrm{X}$ table at a range rate of $11 \%$ to $122 \%, 8 \mathrm{X}$ table at $33 \%$ to $50 \%$ and the $9 \mathrm{X}$ table at a rate of $0 \%$ to $150 \%$ based on the prior knowledge benchmarks set. The $0 \%$ represented the student that had already demonstrated proficiency in the 9X table. All other students had improved their multiplication knowledge from the gamified intervention.

6.2.3. Survey response. The day that I conducted the survey, I had ten students in attendance that participated in the research intervention. In general, the students enjoyed the novel way of learning multiplication $(80 \%)$ and felt they were better at multiplication because of the math magic they had learned. Although extrinsic rewards are believed not to be an effective ways to motivate students, the majority of students indicated they liked receiving 
rewards. Having a leaderboard provided mixed reviews. The leaderboard would only be revealed when I attended the class to update the students on the results. The classroom teacher had utilized leaderboards previously for other purposes in the classroom and had them visible to everyone before I began the research. The majority of students did indicate the leaderboard made them try harder $(70 \%)$ and the same percentage of students identified themselves as being competitive with their classmates. The majority of students felt they were better at multiplication after being exposed to the gamification (90\%). The survey results can be interpreted as students like to have fun and learn in novel ways. Based on the study, the students recognized that they had improved their knowledge of the multiplication tables that are more difficult. Also, $80 \%$ would like to learn other subjects that have been gamified.

6.2.4. Focus group responses. Students were asked about their perception of being taught through using games and gamification. Donald stated that he felt, "It was easier and less pressure". Samantha reported, "We didn't have to get teaching". Although the students were taught multiplication, the different method was not viewed as instruction in the regular sense as their past experiences in the classroom. It can also be interpreted that the classroom setting was perhaps stressful or not enjoyable and a different teaching method would be more receptive to the students. All students reported that they felt they were more successful in learning multiplication using the gamified magic tricks. Thomas and Donald commented that when they saw their name on the leaderboard, they wish they had tried harder. These students were identified by the teacher to be in the low-performing group. These students also experienced the highest rate of improvement in multiplication times tables. The comment about trying harder was further queried, and Donald's response was, "I would get higher and better grades. It helps us learn". Thomas' response was, "Change my attitude; I would not fool around. Take it more seriously". The follow-up question asked was "what would happen if you changed your attitude?" and Thomas' reply was "I would do better and get more points." Thomas was also identified by the teacher as not performing and disengaged from the classroom activities. The students were asked what they would change if they could do the gamification again next year. Susan's response was "Do more Game Master learning. It was more fun and easier to learn math". The consensus for the ten students that participated in the focus group was they found the gamification process fun; they were learning while having fun.

\section{Conclusions}

The research conducted at both the primary school level and the college level is a beginning to identify the impact that gamification has on students. Much more investigation on the introduction of gaming elements into the classroom needs to take place to determine what the impact is on learning. Both scenarios were riddled with limitations. However, the consensus for both groups implied they found the gamified approach to be engaging, motivating and a preferred method to learn.

For the mathematics students there was an improvement in knowledge of the multiplication table. Mathematics is deemed a progressive subject as a sequence of learning must take place to problem solve. The multiplication tables need to be mastered for future mathematics success. The results of this research showed the following improvements: $7 \mathrm{X}$ table improved at a range rate of $11 \%$ to $122 \%, 8 \mathrm{X}$ table at $33 \%$ to $50 \%$ and the $9 \mathrm{X}$ table at a rate of $0 \%$ to $150 \%$. All three abilities groups demonstrated increased learning. Most significant, is that the lowperforming students were engaged in the gamified process and had shown significant improvements based on their prior knowledge. This group had the highest gains in multiplication capacity. These same students presented resistance to participate in the regular classroom and were at times disruptive. They could be described as disengaged and exhibited a learned helplessness or learned hopelessness through observations made within the classroom. However, their enthusiasm and motivation to learn improved when they were placed in smaller groups during the gamified intervention. The self-awareness shown by Thomas (pseudonym) in his comments in the focus group was insightful about his attitude and his abilities. It can be interpreted that he chose to disengage rather than try to learn math in the classroom. In his opinion, he felt that he had more capabilities were not capitalized in the classroom. Thomas recognized that he could do better and would do better with an attitude change.

The business communication college students did express increased motivation and engagement in the classroom because of the gaming process and the associated game elements such as experience points, challenges, and team quests. It is difficult to deem, with the college students, if gamification improved grades or learning aside from the perception the students had about enjoying the course. The approach to learning was a problem-based project which the students felt was a practical way to learn by putting theory into practice compared to textbook learning. The project to raise funds for the charity of their choice offered them autonomy and choice. The philanthropic project attributed to their intrinsic rewards and it can be difficult to separate the project as a key contributor to intrinsic rewards from the gamification elements. However, the competitive nature of the game elements and the leaderboard 
standings did contribute to both intrinsic and extrinsic rewards. It was anticipated that with the majority of students in the classes $(80 \%)$ within the 18 to 25 age group, they would be more involved in games on computers, consoles or phone apps. This was not found and the majority of the students did not play games. Although only $26.7 \%$ of the students played games most of the students enjoyed the gamification process and experiencing gaming elements.

Gamification is not considered a panacea. It can be incorporated without technology and expensive software investments. It is believed that it can be adapted to all age groups from early school age to adults as has been successful in marketing and customer loyalty programs. In this research, it has been recognized as a tool that effectively increased motivation, engagement, and learning. Gamification in education is at the beginning point. Future research would be deemed appropriate. In particular, to gain insight into school opinions from the college students a pre-test survey could be developed to compare opinions with a post-gamification survey. For the mathematics classes, perhaps introduce gamification at an earlier grade level when multiplication is first introduced or at the beginning of the school year.

\section{References}

[1] Sahlberg, P. (2011). Finnish lessons: What can the world learn from educational change in Finland? New York, NY: Teachers College Press, Columbia University.

[2] Areepattamannil, S., Freeman, J. G., \& Klinger, D. A. (2011). Influence of motivation, self-beliefs, and instructional practices in science achievement of adolescents in Canada. Social Psychology of Education: An International Journal, 14(2), 233-259.

[3] Demmert, W. G. (2011). What is culture-based education? Understanding pedagogy and curriculum. In J. Reyhner, W. S. Gilbert \& L. Lockard (Eds.), Honoring our heritage: Culturally appropriate approaches to Indigenous education (pp. 1-9). Flagstaff, AZ: Northern Arizona University.

[4] Foley, D. (2012). Teaching entrepreneurship to Indigenous and other minorities: Towards a strong sense of self, tangible skills and active participation within society. Journal of Business Diversity 12(2), 59-74.

[5] Papp, T. A. (2016). Teacher strategies to improve education outcomes for Indigenous students. Comparative and International Education 45(3), Article 7.

[6] McGonical, J. (2011). Reality is broken: Why games make us better and how they can change the world. New York: Penguin Press.

[7] Deterding, S., Dixon, D., Khaled, T., \& Nacke, L. (2011). From game design elements to gamefullness: Defining "gamification". In A. Lugmayr (Ed.), MindTrek 2011 (pp. 9-15). Tampere, Finland: ACM.
[8] Mood, A. M., \& Specht, R. D. (1954). Gaming as a technique of analysis. Alexandria, VA: Department of Defense.

[9] Caillois, R. (2001). Man, play and games. Chicago, IL: University of Illinois Press.

[10] Erenli, K. (2013). The impact of gamification: Recommending education scenarios. International Journal of Emerging Technologies in Learning 8(1), 15-21.

[11] Kapp, K. M. (2012). The gamification of learning and instruction: Game-based methods and strategies for training and education. San Francisco, CA: John Wiley \& Sons, Inc.

[12] Gee, J. P. (2007). What video games have to teach us about learning and literacy. (Rev. Ed.) New York, NY: Palgrave Macmillan.

[13] Ryan, R. M., \& Deci, E. L. (2000). Intrinsic and extrinsic motivations: Classic definitions and new directions. Contemporary Educational Psychology 25(1), 54-67.

[14] Bandura, A. (1986). Social foundations of thought and action: A social cognitive theory. Englewood Cliffs, NJ: Prentice-Hall.

[15] Ratner, N., \& Bruner, J. (1978). Games, social exchange and the acquisition of language. Journal of Child Language 5, 391-401.

[16] Keller, J. (2008). An integrative theory of motivation, volition, and performance. Technology, Instruction, Cognition, and Learning 6, 79-104.

[17] Csikszentmihalyi, M. (1990). Flow: The psychology of optimal experience. New York, NY: Harper \& Row.

[18] Nah, F. F,-H., Zeng, Q., Telaprolu, R., Ayyappa, A. P., \& Eschenbrenner, B. (2014). Gamification of Education: A review of literature. In F. F.-H. Nah (Ed.) HCI in Business, (pp. 401-409). Heraklion, Greece: Springer.

[19] Lee, J. J., \& Hammer, J. (2011). Gamification in education: What, how, why bother? Academic Exchange Quarterly, 15(2), 1-5.

[20] Dicheva, D., Dichev, C., Agre, G., \& Angelova, G. (2015). Gamification in education: A systematic mapping study. Education Technology \& Society 18(3), 1-10.

[21] Sheldon, L. (2012). The multiplayer classroom: Designing coursework as a game. Boston, MA: Course Technology.

[22] Granic, I., Lobel, A., \& Engels, R. C. M. E. (2014). The benefits of playing video games. American Psychology 69(1), 66-78.

[23] Glaser, B. G., \& Strauss, A. (1967). The discovery of grounded theory. Chicago, IL: Aldine Publishing.

[24] Glaser, B. G. (2002). Grounded theory and gender relevance. Health Care for Women International 23, 786793. 
[25] McMillan, J. H., \& Schumacher, S. (2010). Research in education: Evidence-based inquiry, (7th ed.). Upper Saddle River, NJ: Pearson.

[26] Creswell, J. W., \& Clark, V. L. P. (2007). Designing and conducting mixed methods research. Los Angeles, CA: Wiley.

[27] Creswell, J. W. (2013). Research design: Qualitative, quantitative, and mixed methods approaches. Thousand Oaks, CA: SAGE. 